\title{
Rastreabilidade de farinha de vísceras de aves por isótopos estáveis em penas de frangos de corte
}

\author{
Priscila Cavalca de Araujo(1), José Roberto Sartori(1), Valquíria Cação da Cruz ${ }^{(2)}$, \\ Antonio Celso Pezzato(1), Carlos Ducatti ${ }^{(3)}$, Ana Cristina Stradiotti ${ }^{(1)}$ e Vanessa Cristina Pelícia(1) \\ (1)Universidade Estadual Paulista (Unesp), Faculdade de Medicina Veterinária e Zootecnia, Departamento de Melhoramento Zootécnico \\ e Nutrição Animal, Distrito de Rubião Júnior, s/no, Caixa Postal 510, CEP 18618-000 Botucatu, SP. E-mail: pricavalca@hotmail.com, \\ jrsatori@fmvz.unesp.br, cpezzato@fmvz.unesp.br, ana.stradiotti@hotmail.com, vcpelicia@yahoo.com.br(2)Unesp, Campus Experimental de \\ Dracena, Rodovia Comandante João Ribeiro de Barros, SP 294, Km 651, CEP 17900-000 Dracena, SP. E-mail: valquíria@dracena.unesp.br \\ (3)Unesp, Instituto de Biociências, Centro de Isótopos Estáveis, Distrito de Rubião Júnior, s/nº, Caixa Postal 510, CEP 18618-000 Botucatu, SP. \\ E-mail: ducatti@ibb.unesp.br
}

\begin{abstract}
Resumo - O objetivo deste trabalho foi detectar a presença de farinha de vísceras de aves (FV) na alimentação de frangos de corte, por meio da análise de penas por isótopos estáveis de carbono $\left({ }^{13} \mathrm{C} /{ }^{12} \mathrm{C}\right) \mathrm{e}$ nitrogênio $\left({ }^{15} \mathrm{~N} /{ }^{14} \mathrm{~N}\right)$ e espectrofotometria de massas. Setecentos e vinte pintos machos Cobb foram submetidos aos seguintes tratamentos: ração vegetal (RV) à base de milho e farelo de soja, de 1 a 42 dias de idade; ração com $8 \%$ de farinha de vísceras de frango (FV), de 1 a 42 dias de idade; ração vegetal de 1 a 21 dias e ração com FV de 22 a 42 dias; ração vegetal de 1 a 35 dias e ração com FV de 36 a 42 dias; ração com FV de 1 a 21 dias, e ração vegetal de 22 a 42 dias; ração com FV de 1 a 35 dias, e ração vegetal de 36 a 42 dias. Foram colhidas amostras de penas de quatro aves por tratamento aos $7,14,21,28,35$ e 42 dias de idade, que foram submetidas à análise isotópica de carbono $\left({ }^{13} \mathrm{C} /{ }^{12} \mathrm{C}\right)$ e nitrogênio $\left({ }^{15} \mathrm{~N} /{ }^{14} \mathrm{~N}\right)$ por espectrometria de massas. A aplicação da técnica dos isótopos estáveis de $\mathrm{C}$ e $\mathrm{N}$ a penas de frango de corte, após a utilização de farinha de vísceras na alimentação de frangos de corte, pelo período de até 21 dias, permite detectar a inclusão da FV na dieta.
\end{abstract}

Termos para indexação: carbono-13, certificação, farinha de origem animal, nitrogênio-15.

\section{Traceability of poultry viscera meal by stable isotopes in broiler feathers}

\begin{abstract}
The objective of this work was to evaluate the presence of poultry viscera meal (VM) in the diet of broiler chikens, through the feather analyses by stable isotopes of carbon $\left({ }^{13} \mathrm{C} /{ }^{12} \mathrm{C}\right)$ and nitrogen $\left({ }^{15} \mathrm{~N} /{ }^{14} \mathrm{~N}\right)$ and mass spectrophotometry. Seven hundred and twenty Cobb male broiler chicks were subjected to the following treatments: vegetable diet (VD) based on corn and soybean meal, from 1 to 42 days of age; diet with $8 \%$ poultry viscera meal (VM), from 1 to 42 days of age; vegetable diet from 1 to 21 days, and diet with VM from 22 to 42 days; vegetable diet from 1 to 35 days, and diet with VM from 36 to 42 days; diet with VM from 1 to 21 days and, and vegetable diet from 22 to 42 days; diet with VM from 1 to 35 days, and vegetable diet from 36 to 42 days. Feather samples were collected from four birds per treatment at 7, 14, 21, 28, 35 and 42 days of age, which were subjected to isotopic analysis for carbon $\left({ }^{13} \mathrm{C} /{ }^{12} \mathrm{C}\right)$ and nitrogen $\left({ }^{15} \mathrm{~N} /{ }^{14} \mathrm{~N}\right)$ by mass spectrometry. The use of the stable $\mathrm{C}$ and $\mathrm{N}$ isotope technique in feathers allow the VM detection in broiler chicken diet after 21 days of VM inclusion.
\end{abstract}

Index terms: carbon-13, certification, meal of animal origin, nitrogen-15.

\section{Introdução}

A avicultura brasileira destacou-se nas últimas décadas por uma trajetória de expressivo incremento tecnológico. A inserção e a manutenção dos produtos avícolas brasileiros no mercado externo, em níveis competitivos, a maior demanda por produtos processados e as ocorrências de contaminações de alimentos e bebidas por patógenos ou resíduos têm levado à modificações e reestruturações no setor produtivo de alimentos.
Essas modificações dependem da constante busca da qualidade e do menor custo de produção. As barreiras sanitárias impostas pelos países importadores de carne de frango e os cuidados extremos que começam na escolha da matéria-prima utilizada na alimentação das aves também influenciam essas modificações. A maior preocupação será sempre a certificação e a prevenção da contaminação desses produtos; porém, uma vez certificados, os esforços são direcionados para minimizar ao máximo os efeitos e prejuízos decorrentes da contaminação (Cima et al., 2006). 
A segurança alimentar é a característica mais valorizada pelo mercado no processo de escolha de um determinado produto. $\mathrm{O}$ mercado exige transparência quanto às condições e aos métodos de produção do alimento. Com isso, surgiu o conceito de rastreabilidade, uma ferramenta para fornecer maior segurança ao consumidor (Silva, 2004).

$\mathrm{O}$ termo rastreabilidade refere-se à capacidade de traçar o histórico, a aplicação ou a localização de um item por meio de informações previamente registradas. É importante atentar para o fato de que, sob o manto da rastreabilidade, também podem aparecer outros interesses, além da qualidade, da segurança alimentar e da sanidade animal, que podem ser usados como barreira comercial, para dificultar as exportações ou importações de um país (Silva, 2004).

O único sistema de rastreabilidade oficialmente implantado no Brasil, é o da cadeia de bovinos e bubalinos, denominado Sisbov - Sistema Brasileiro de Identificação e Certificação de Origem Bovina e Bubalina, criado em 2002 como resposta imediata às pressões da União Europeia, que exigia um programa oficial de rastreabilidade para a cadeia de bovinos.

Em relação à rastreabilidade de alimentos de origem animal, as empresas estão adotando sistemas para melhorar o controle de qualidade de seus produtos e o impacto ao meio ambiente e à sociedade.

Muitos métodos têm sido propostos para identificar a presença de subprodutos de origem animal em rações para animais, tais como hibridização de DNA, ELISA e PCR (Block Junior, 2002). A espectrometria de massas, por meio da análise da razão isotópica para o carbono-13, tem sido usada com sucesso para testar a autenticidade, a qualidade e a origem geográfica de vários produtos, tais como: suco de frutas, (Bricout \& Koziet, 1987; Koziet et al., 1993); vinhos, (Martin et al., 1988); mel, (Brookes et al., 1991; White et al., 1998); produtos lácteos (Rossmann et al., 2000; Manca et al., 2001); e óleos vegetais, (Kelly et al., 1997).

A espectrometria de massas, pela análise da razão isotópica de $\mathrm{C}$ associado a $\mathrm{N}$, no produto final, foi utilizada por Carrijo et al. (2006) e Oliveira et al. (2010) em pesquisas com frangos de corte, em que determinaram a presença de farinha de origem animal e farinha de vísceras de aves, respectivamente, na alimentação das aves. Nessa mesma linha de pesquisa, Móri et al. (2007) e Denadai et al. (2009) também identificaram a presença de farinha de origem animal em dieta de animais, pela análise da carne de codornas e ovos de poedeiras comerciais, respectivamente.

$\mathrm{O}$ objetivo deste trabalho foi avaliar a presença de isótopos estáveis de carbono $\left({ }^{13} \mathrm{C} /{ }^{12} \mathrm{C}\right)$ e nitrogênio $\left({ }^{15} \mathrm{~N} /{ }^{14} \mathrm{~N}\right)$ em penas de frangos de corte provenientes de farinha de vísceras (FV) fornecidas na ração.

\section{Material e Métodos}

O experimento foi realizado no Laboratório de Nutrição de Aves, Faculdade de Medicina Veterinária e Zootecnia, do Campus de Botucatu da Universidade Estadual Paulista, entre 21 de abril 22 e de junho de 2008. Foram utilizados 720 pintinhos de corte machos, da linhagem Cobb, com um dia de idade, distribuídos em um delineamento em blocos ao acaso, com seis tratamentos e quatro repetições. As aves foram criadas em galpão experimental, dividido em 24 boxes de $2,5 \mathrm{~m}^{2}$, em piso com 30 aves por boxe, à densidade de 12 aves $\mathrm{m}^{-2}$. Vacinadas contra Gumboro, via água de bebida aos 10 e 20 dias de idade, as aves foram criadas até os 42 dias de idade.

Inicialmente, cada boxe continha um bebedouro tipo copo de pressão, para o fornecimento de água, e um comedouro tipo tubular inicial, para o fornecimento da ração. Estes equipamentos foram substituídos gradativamente por bebedouro pendular e comedouro tubular definitivos, um para cada boxe, respectivamente. A água e a ração foram fornecidas à vontade durante todo o período experimental. Para o aquecimento inicial dos pintos, cada boxe foi equipado com uma campânula, com lâmpada infravermelha de $250 \mathrm{~W}$, que foi retirada no sétimo dia de idade dos pintos.

O programa de arraçoamento foi dividido em fases: 1-35 dias e 36-42 dias (Tabela 1). As rações, isoproteicas e isoenergéticas, foram formuladas à base de milho, farelo de soja, óleo de soja, fosfato bicálcico, calcário calcítico, sal comum, DL-metionina, L-lisina, suplementos vitamínico e mineral, conforme adaptações das recomendações de Rostagno et al. (2005). A percentagem de inclusão de FV na dieta foi estipulada em $8 \%$, de acordo com informações a respeito das quantidades adotadas pelas empresas produtoras de frangos de corte.

As aves foram submetidas a seis tratamentos experimentais, de acordo com os seguintes grupos: RV (1-42), ração vegetal (RV) à base de milho e farelo de soja, sem subproduto de origem animal, de 1 a 
42 dias de idade; FV (1-42), ração com FV de 1 a 42 dias; FV (22-42), RV de 1 a 21 dias e FV de 22 a 42 dias; FV (35-42), RV de 1 a 35 dias e FV de 36 a 42 dias; FV (1-21), FV de 1 a 21 dias e RV de 22 a 42 dias; FV (1-35), FV de 1 a 35 dias e RV de 36 a 42 dias.

A cada coleta, aos 7, 14, 21, 28, 35 e 42 dias de idade, foram tomadas aleatoriamente quatro aves por tratamento, das quais foram colhidas amostras de penas, retiradas manualmente da região do peito, devidamente identificadas, acondicionadas em

Tabela 1. Composição percentual de ingredientes e teores nutricionais das rações experimentais sem $(0 \%)$ e com $(8 \%)$ de farinha de vísceras para frangos de 1 a 35 dias e de 36 a 42 dias de idade.

\begin{tabular}{|c|c|c|c|c|}
\hline \multirow[t]{2}{*}{ Ingredientes } & \multicolumn{2}{|c|}{$1-35$ dias } & \multicolumn{2}{|c|}{$36-42$ dias } \\
\hline & $0 \%$ & $8 \%$ & $0 \%$ & $8 \%$ \\
\hline Milho, grão & 57,7 & 65,16 & 63,25 & 70,66 \\
\hline Soja, farelo & 35,56 & 23,9 & 29,82 & 18,18 \\
\hline Vísceras, farinha & 0 & 8 & 0 & 8 \\
\hline Soja, óleo & 2,64 & 0,1 & 3,11 & 0,59 \\
\hline Calcário calcítico & 0,98 & 0,82 & 0,94 & 0,77 \\
\hline Fosfato bicálcico & 1,83 & 0,8 & 1,63 & 0,60 \\
\hline DL - Metionina & 0,23 & 0,20 & 0,22 & 0,18 \\
\hline $\mathrm{L}-$ Lisina & 0,16 & 0,22 & 0,22 & 0,28 \\
\hline Colina, cloreto $(70 \%)$ & 0,04 & 0,04 & 0,04 & 0,04 \\
\hline Sal comum & 0,46 & 0,36 & 0,38 & 0,30 \\
\hline$\underline{\text { Suplemento vitamínico-mineral }}^{(1)}$ & 0,40 & 0,40 & 0,40 & 0,40 \\
\hline Total & 100 & 100 & 100 & 100 \\
\hline \multicolumn{5}{|l|}{ Teores nutricionais } \\
\hline Energia metabolizável $\left(\mathrm{kcal}^{-1} \mathrm{~kg}\right)$ & 3.000 & 3.000 & 3.100 & 3.100 \\
\hline Proteína bruta $(\%)$ & 21,40 & 21,40 & 19,30 & 19,30 \\
\hline Cálcio (\%) & 0,96 & 0,96 & 0,88 & 0,88 \\
\hline Fósforo disponível (\%) & 0,45 & 0,45 & 0,41 & 0,41 \\
\hline Metionina (\%) & 0,56 & 0,56 & 0,51 & 0,51 \\
\hline Metionina + cistina $(\%)$ & 0,90 & 0,90 & 0,83 & 0,83 \\
\hline Lisina $(\%)$ & 1,26 & 1,26 & 1,16 & 1,16 \\
\hline
\end{tabular}

${ }^{(1)}$ Suplemento vitamínico-mineral inicial Vaccinar (níveis de garantia por quilograma de ração): vitamina A, 14.000 UI; vitamina D3, 2.500 UI; vitamina $\mathrm{E}, 25,00 \mathrm{mg}$; vitamina $\mathrm{K} 3,3,00 \mathrm{mg}$; vitamina $\mathrm{B} 1,2,00 \mathrm{mg}$; vitamina B2, 5,00 mg; vitamina B6, 4,00 mg; vitamina B12, 25,00 mcg; niacina, $35 \mathrm{mg}$; ácido pantotênico, $12,00 \mathrm{mg}$; biotina, $0,10 \mathrm{mg}$; ácido fólico, 1,00 mg; colina, 800,00 mg; antioxidante (B.H.T.), 2,00 mg; selênio, 0,18 mg; ferro, $50,10 \mathrm{mg}$; manganês, 78,00 mg; iodo, 0,70 mg; cobre, 10,00 mg; zinco, 55,00 mg. Suplemento vitamínico-mineral crescimento Vaccinar (níveis de garantia por quilograma de ração): vitamina A, $10.000 \mathrm{UI}$; vitamina D3, $2.000 \mathrm{UI}$; vitamina K3, 2,00 mg; vitamina B1, 2,00 mg; vitamina B2, 4,00 mg; vitamina B6, 4,00 mg; vitamina B12, 20,00 mcg; niacina, 30,00 mg; ácido pantotênico, 10,00 mg; biotina, 0,06 mg; ácido fólico, 1,00 mg; colina, 600,00 mg; antioxidante (B.H.T.), 2,00 mg; selênio, 0,18 mg; ferro, 50,10 mg; manganês, 78,00 mg; iodo, 0,70 mg; cobre, 10,00 mg; zinco, 55,00 mg. embalagens individuais e congeladas para posterior análise isotópica.

As análises isotópicas das amostras das penas e rações foram realizadas no Centro de Isótopos Estáveis Ambientais, do Instituto de Biociências, Campus de Botucatu, da Unesp. As penas foram descongeladas e lavadas em água destilada, para remover qualquer contaminação de ração e excretas e, em seguida, foram secas em estufa de ventilação forçada, a $50^{\circ} \mathrm{C}$ por 24 horas. Sobre uma placa de Petri, foram cortadas finamente com tesoura e lâmina até que ficassem o mais homogêneas possível. Foram pesadas em cápsulas de estanho, aproximadamente 50 a $60 \mu \mathrm{g}$ e 500 a $600 \mu \mathrm{g}$ de amostras, para a determinação das razões isotópicas do carbono e nitrogênio, respectivamente. As cápsulas foram introduzidas, por meio de amostrador automático no analisador elementar EA 1108 CHN, (Fisons Instruments, Rodano, Itália), em que, em presença de oxigênio e óxido de cobre $(\mathrm{CuO})$, a amostra foi queimada quantitativamente para a obtenção de $\mathrm{CO}_{2}$ e $\mathrm{NO}_{2}$; este último foi, então, reduzido a $\mathrm{N}_{2}$ na presença de cobre. Os gases formados foram separados em coluna cromatográfica gasosa e analisados no espectrômetro de massas de razões isotópicas Delta $\mathrm{S}$, (Finnigan MAT, Bremen, Alemanha).

Os resultados das análises foram expressos em delta per mil $(\delta \%)$ relativos aos padrões internacionais: Peedee Belemnite (PDB) para $0{ }^{13} \mathrm{C}$ e nitrogênio atmosférico para ${ }^{15} \mathrm{~N}$, de acordo com a seguinte equação geral $\delta \mathrm{X}($ amostra, padrão $)=[($ Ramostra - Rpadrão $) /$ Rpadrão]1000, em que: $\delta X$ é o enriquecimento do isótopo mais pesado do elemento químico $\mathrm{X}(\mathrm{C}$ ou N) da amostra, em relação ao respectivo padrão internacional; e $\mathrm{R}$ é a razão isotópica entre os isótopos menos e mais abundante, ${ }^{13} \mathrm{C} /{ }^{12} \mathrm{C}$ e ${ }^{15} \mathrm{~N} /{ }^{14} \mathrm{~N}$.

Os resultados isotópicos obtidos foram submetidos à análise multivariada de variância (MANOVA), com auxílio do procedimento GLM do programa estatístico do SAS Institute (2000). A partir dos dados gerados pelas matrizes de erro, foram determinadas regiões com $95 \%$ de confiança, para verificar as diferenças entre as médias dos tratamentos.

\section{Resultados e Discussão}

Os valores de $\delta^{15} \mathrm{~N}$ das rações de frango de corte aumentaram tanto da dieta vegetal para a dieta com $\mathrm{FV}$, como das rações ofertadas às aves de 1-21 dias 
para as de 22-42 dias de idade, em uma mesma dieta (Tabela 2). Isso, provavelmente, ocorreu em razão das variações na composição percentual dos ingredientes nas rações. As rações da dieta com FV continham menor quantidade de farelo de soja e maior quantidade de milho, em comparação às rações da dieta vegetal. $O$ aumento observado nas rações de 1-21 para as de $22-42$ dias pode ser atribuído ao mesmo fato, pois as rações de 22-42 dias também continham menor percentual de farelo de soja. $O$ milho $\left(\delta^{13} \mathrm{C}=-12,15 \pm 0,04 \%\right.$ o e $\delta^{15} \mathrm{~N}=6,81 \pm 0,04 \%$ o), farelo de soja $\left(\delta^{13} \mathrm{C}=-26,15 \pm 0,10 \%\right.$ e $\delta^{15} \mathrm{~N}=0,55 \pm 0,04 \%$ ) e a farinha de vísceras $\left(\delta^{13} \mathrm{C}=-16,85 \pm 0,13 \%\right.$ e $\delta^{15} \mathrm{~N}=4,07 \pm 0,10 \%$ ), utilizados na confecção das rações, também foram analisados isotopicamente quanto ao conteúdo de nitrogênio e carbono. A soja possui valor de $\delta^{15} \mathrm{~N}$ que se aproxima ao valor do $\mathrm{N}_{2}$ atmosférico $\left(\delta^{15} \mathrm{~N}=0,0 \pm 1,0 \%\right.$ ), pois fixa o nitrogênio do ar e apresenta fator de fracionamento de $\delta^{15} \mathrm{~N}$ ao redor da unidade, ficando geralmente abaixo de 1,003\%o (Kohl \& Shearer, 1980; Handley \& Raven, 1992; Werner \& Schmidt, 2002). O valor de $\delta^{15} \mathrm{~N}$, apresentado por plantas que não fixam o nitrogênio atmosférico, depende, em grande parte, da abundância desse isótopo no solo e de adubos administrados, como é o caso do milho (Choi et al., 2002). Sleiman et al. (2004) avaliaram amostras de milho de alguns estados brasileiros e encontraram valores médios de $4,77 \pm 1,16 \%$ para $\delta^{15} \mathrm{~N}$ e $-11,74 \pm 0,40 \%$ para $\delta^{13} \mathrm{C}$, respectivamente.

A exemplo do aumento, descrito acima, ocorrido no $\delta^{15} \mathrm{~N}$, o mesmo fato foi observado para os valores de $\delta^{13} \mathrm{C}$ nas rações experimentais, pois, ao se incluir FV na formulação da ração, foi requerida menor quantidade de farelo e óleo de soja para seu balanceamento, em comparação à ração vegetal isoenergética e isoproteica correspondente. Além disso, aumentou-se a inclusão

Tabela 2. Médias \pm desvios-padrão dos valores isotópicos de $\delta^{13} \mathrm{C}$ e $\delta^{15} \mathrm{~N}$, das rações de frangos de corte com inclusão de farinha de vísceras (FV) criados até os 42 dias de idade.

\begin{tabular}{lccc}
\hline Ração & FV $(\%)$ & $\delta^{13} \mathrm{C}^{(1)}$ & $\delta^{15} \mathrm{~N}^{(1)}$ \\
\hline Inicial & 0 & $-17,72 \pm 0,25$ & $1,75 \pm 0,18$ \\
1 a 21 dias de idade & 8 & $-16,22 \pm 0,10$ & $2,67 \pm 0,11$ \\
\hline Crescimento & 0 & $-17,09 \pm 0,16$ & $1,85 \pm 0,24$ \\
22 a 42 dias de idade & 8 & $-15,76 \pm 0,07$ & $3,26 \pm 0,10$ \\
\hline
\end{tabular}

${ }^{(1)}$ Valores isotópicos médios, expressos em $\delta^{13} \mathrm{C}$ e $\delta^{15} \mathrm{~N}$, relativos aos padrões PeeDee Belemnite (PDB) e nitrogênio atmosférico $\left(\mathrm{N}_{2}\right)$, respectivamente. do ingrediente energético, nesse caso, o milho. Isso acontece porque plantas do ciclo fotossintético $\mathrm{C}_{3}$ (soja, arroz, trigo) possuem valor modal de $\delta^{13} \mathrm{C}=-27,6 \%$, em relação ao padrão PeeDee Belemnite (PDB) e, nas plantas do ciclo fotossintético $\mathrm{C}_{4}$ (milho, sorgo, cana-de-açúcar), esse valor é de $\delta^{13} \mathrm{C}=-12,6 \%$ (Vogel et al., 1993). As rações para aves de 22-42 dias seriam mais ricas em ${ }^{13} \mathrm{C}$, em comparação às rações de 1-21 dias, pois, em termos nutricionais, são mais energéticas e menos proteicas, o que faz com que a composição percentual dos ingredientes mude na mesma dieta, embora esses valores possam não apresentar diferenças significativas. Para tanto, as rações para aves de 22-42 dias teriam maior quantidade de milho e menor quantidade de farelo de soja.

Esses apontamentos relativos aos valores de $\delta^{13} \mathrm{C}$ e $\delta^{15} \mathrm{~N}$ das rações de frangos de corte, assim como de outras espécies, mostram-se fundamentais para a identificação da presença de subprodutos de origem animal na alimentação, uma vez que a assinatura isotópica da dieta fica marcada no organismo dos animais. Segundo DeNiro \& Epstein (1978), o animal é aquilo que consome isotopicamente até $\pm 2,0 \%$ para $\delta^{13} \mathrm{C}$ e até $\pm 3,0 \%$ para $\delta^{15} \mathrm{~N}$, embora cada tecido possa apresentar assinatura isotópica, fator de fracionamento (Hobson \& Clark, 1992b) e turnover isotópico particulares (Hobson \& Clark, 1992a).

Os valores médios de $\delta^{13} \mathrm{C}$ e $\delta^{15} \mathrm{~N}$, para as penas dos frangos de corte, alimentados com os tratamentos experimentais, contidos na Tabela 3, mostraram enriquecimento tanto em carbono quanto em nitrogênio em comparação ao tratamento controle.

Os tratamentos são considerados diferentes do controle (dieta vegetal), quando a diferença entre suas médias de $\delta^{13} \mathrm{C}$ e $\delta^{15} \mathrm{~N}$ forem diferentes de zero e, assim, a região de confiança não se sobrepõe a nenhum dos eixos do gráfico (Figura 1). O fato de as elipses se sobreporem a um dos eixos mostra que não há diferença entre as médias de $\delta^{13} \mathrm{C}$ e $\delta^{15} \mathrm{~N}$ dos tratamentos comparados com o controle (RV 1-42d).

Aos sete dias de idade, nas penas, os tratamentos FV 1-42 dias, FV 1-21 dias e FV 1-35 dias não diferiram do tratamento vegetal, pois suas elipses se sobrepuseram ao eixo das diferenças de $\delta^{13} \mathrm{C}$ (Figura 1 A). Esse fato ocorreu, provavelmente, pelo fato de, aos sete dias de idade, as penas ainda não terem sido trocadas (penugem) e ainda terem o sinal isotópico da matriz. 
Aos 14 dias de idade, as dietas com FV ainda não diferiram da dieta vegetal, e este período ainda não foi suficiente para incorporar o sinal isotópico da alimentação nas penas (Figura $1 \mathrm{~B}$ ). Entretanto, o período de 21 dias foi suficiente para a incorporação do sinal nas penas, nos tratamentos que receberam dieta com FV, FV 1-42, FV 1-21 e FV 1-35 (Figura 1 C).

Aos 28 dias, os tratamentos FV 1-42 dias, FV 1-21 dias e FV 1-35 dias diferiram das aves do tratamento vegetal, pois suas regiões de confiança não se sobrepuseram a nenhum dos eixos

Tabela 3. Médias \pm desvios-padrão dos valores isotópicos de $\delta 13 \mathrm{C}$ e $\delta 15 \mathrm{~N}$, detectados em penas de frangos de corte criados até os 42 dias de idade.

\begin{tabular}{|c|c|c|c|}
\hline Idade & Tratamento $^{(1)}$ & $\delta^{13} \mathrm{C} \pm \mathrm{DP}$ & $\delta^{15} \mathrm{~N} \pm \mathrm{DP}$ \\
\hline & RV $1-42 d$ & $-18,6 \pm 0,20$ & $5,86 \pm 0,33$ \\
\hline \multirow[t]{4}{*}{7 dias } & FV $1-42 d$ & $-17,77 \pm 0,22$ & $6,11 \pm 0,13$ \\
\hline & FV $1-35 d$ & $-17,97 \pm 0,10$ & $6,19 \pm 0,08$ \\
\hline & FV 1-21d & $-17,65 \pm 0,22$ & $6,14 \pm 0,14$ \\
\hline & RV $1-42 d$ & $-18,07 \pm 0,31$ & $5,65 \pm 0,23$ \\
\hline \multirow[t]{5}{*}{14 dias } & FV $1-42 d$ & $-17,41 \pm 0,27$ & $6,18 \pm 0,25$ \\
\hline & FV 1-35d & $-17,70 \pm 0,14$ & $6,11 \pm 0,30$ \\
\hline & FV 1-21d & $-17,62 \pm 0,07$ & $5,88 \pm 0,18$ \\
\hline & RV $1-42 d$ & $-18,94 \pm 0,11$ & $3,32 \pm 0,05$ \\
\hline & FV $1-42 d$ & $-16,89 \pm 0,13$ & $4,64 \pm 0,07$ \\
\hline \multirow[t]{4}{*}{21 dias } & FV $1-35 d$ & $-17,16 \pm 0,10$ & $4,65 \pm 0,09$ \\
\hline & FV 1-21d & $-17,23 \pm 0,15$ & $4,39 \pm 0,15$ \\
\hline & RV $1-42 d$ & $-18,57 \pm 0,20$ & $3,62 \pm 0,07$ \\
\hline & FV $1-42 d$ & $-16,94 \pm 0,21$ & $4,68 \pm 0,08$ \\
\hline \multirow[t]{5}{*}{28 dias } & FV $1-35 d$ & $-17,14 \pm 0,17$ & $4,73 \pm 0,10$ \\
\hline & FV 1-21d & $-17,85 \pm 0,18$ & $4,16 \pm 0,06$ \\
\hline & FV $22-42 d$ & $-18,06 \pm 0,26$ & $3,93 \pm 0,21$ \\
\hline & RV $1-42 d$ & $-18,85 \pm 0,07$ & $3,81 \pm 0,12$ \\
\hline & FV $1-42 d$ & $-16,92 \pm 0,11$ & $4,97 \pm 0,08$ \\
\hline \multirow[t]{5}{*}{35 dias } & FV $1-35 d$ & $-16,85 \pm 0,28$ & $4,97 \pm 0,09$ \\
\hline & FV 1-21d & $-17,93 \pm 0,17$ & $4,14 \pm 0,16$ \\
\hline & FV $22-42 d$ & $-17,75 \pm 0,26$ & $4,36 \pm 0,18$ \\
\hline & RV $1-42 d$ & $-18,65 \pm 0,20$ & $3,87 \pm 0,21$ \\
\hline & FV $1-42 d$ & $-16,92 \pm 0,26$ & $5,07 \pm 0,12$ \\
\hline \multirow[t]{4}{*}{42 dias } & FV 1-35d & $-17,04 \pm 0,06$ & $4,59 \pm 0,05$ \\
\hline & FV 1-21d & $-18,24 \pm 0,09$ & $4,10 \pm 0,11$ \\
\hline & FV $22-42 d$ & $-17,29 \pm 0,26$ & $4,93 \pm 0,08$ \\
\hline & FV 36-42d & $-18,62 \pm 0,01$ & $3,82 \pm 0,11$ \\
\hline
\end{tabular}

${ }^{(1)} \mathrm{RV}$ 1-42d, ração vegetal à base de milho e farelo de soja, sem subproduto de origem animal (ração basal), em frangos com 1 a 42 dias de idade; FV $1-42$ d, ração com $8 \%$ de farinha de vísceras de frango (FV), em frangos com 1 a 42 dias de idade; FV 1-35d, ração com $8 \%$ de FV, em frangos com 1 a 35 dias, e ração basal em frangos com 36 a 42 dias de idade; FV 1-21d, ração com $8 \%$ de FV, em frangos com 1 a 21 dias, e ração basal em frangos com 22 a 42 dias de idade;. FV 22-42d, ração basal em frangos com 1 a 21 dias, e ração com $8 \%$ de FV em frangos com 22 a 42 dias de idade; FV $35-42$ d, ração basal em frangos com 1 a 35 dias, e ração com $8 \%$ de FV em frangos com 36 a 42 dias de idade.
(Figura 1 D), e o tratamento FV 22-42 dias, que trocou a dieta vegetal por dieta com FV após 21 dias, não diferiu do tratamento vegetal, o que indica que estes sete dias de consumo não foram suficientes para incorporar o sinal isotópico da nova alimentação.

Aos 35 dias, verificou-se que as aves dos tratamentos FV 1-42 dias, FV 22-42 dias e FV 1-35 dias diferiram do tratamento vegetal, pois suas regiões de confiança não se sobrepuseram a nenhum dos eixos no gráfico (Figura 1 E). As aves do tratamento FV 1-21 dias não diferiu do tratamento vegetal, pois suas elipses se sobrepuseram ao eixo, do que se conclui que 14 dias da troca da dieta foram suficientes para tornar o sinal igual ao da dieta vegetal. Estes resultados são semelhantes aos encontrados por Oliveira et al. (2010), que avaliaram o sinal isotópico de $\mathrm{C}$ e $\mathrm{N}$ no músculo peitoral, na quilha e na tíbia de frangos de corte, que receberam dieta que continha farinha de vísceras em substituição à dieta vegetal, e verificaram que o período de 14 dias foi suficiente para incorporar, nesses tecidos, o sinal isotópico da nova dieta.

Aos 42 dias, observa-se que as aves dos tratamentos FV 1-42 dias, FV 22-42 dias e FV 1-35 dias diferiram do tratamento vegetal, pois suas regiões de confiança não se sobrepuseram a nenhum dos eixos (Figura $1 \mathrm{~F}$ ). Nas aves do tratamento FV 35-42 dias, em que as aves ingeriram dieta com farinha de vísceras por sete dias, observa-se que este período não foi suficiente para incorporar o sinal isotópico da alimentação. As aves do tratamento FV 1-21 dias, que receberam apenas a dieta com $\mathrm{FV}$ até 21 dias, também não diferiram das aves do tratamento vegetal, pois, aos 35 dias de idade, esta alteração de sinal já havia se manifestado.

Cruz et al. (2008) analisaram fígados de frangos de corte, aos 42 dias de idade, que consumiram farinha de vísceras até 21 dias idade, e verificaram assinatura isotópica semelhante às das aves do grupo controle (dieta vegetal), sem detectar o uso da farinha de vísceras na alimentação dessas aves pela análise isotópica de ${ }^{13} \mathrm{C}$ $\mathrm{e}^{15} \mathrm{~N}$. Assim, em razão do rápido turnover desse tecido, ele não seria um bom indicador nessas condições. No caso das penas, os sinais isotópicos encontrados na presente pesquisa permitiram a detecção do uso da farinha de vísceras, na dieta das aves que consumiram FV até 21 dias, ao se analisarem as penas aos 42 dias de idade.

Tecidos como as penas, de lenta alteração de sinal isotópico em consequência da dieta, podem compor 

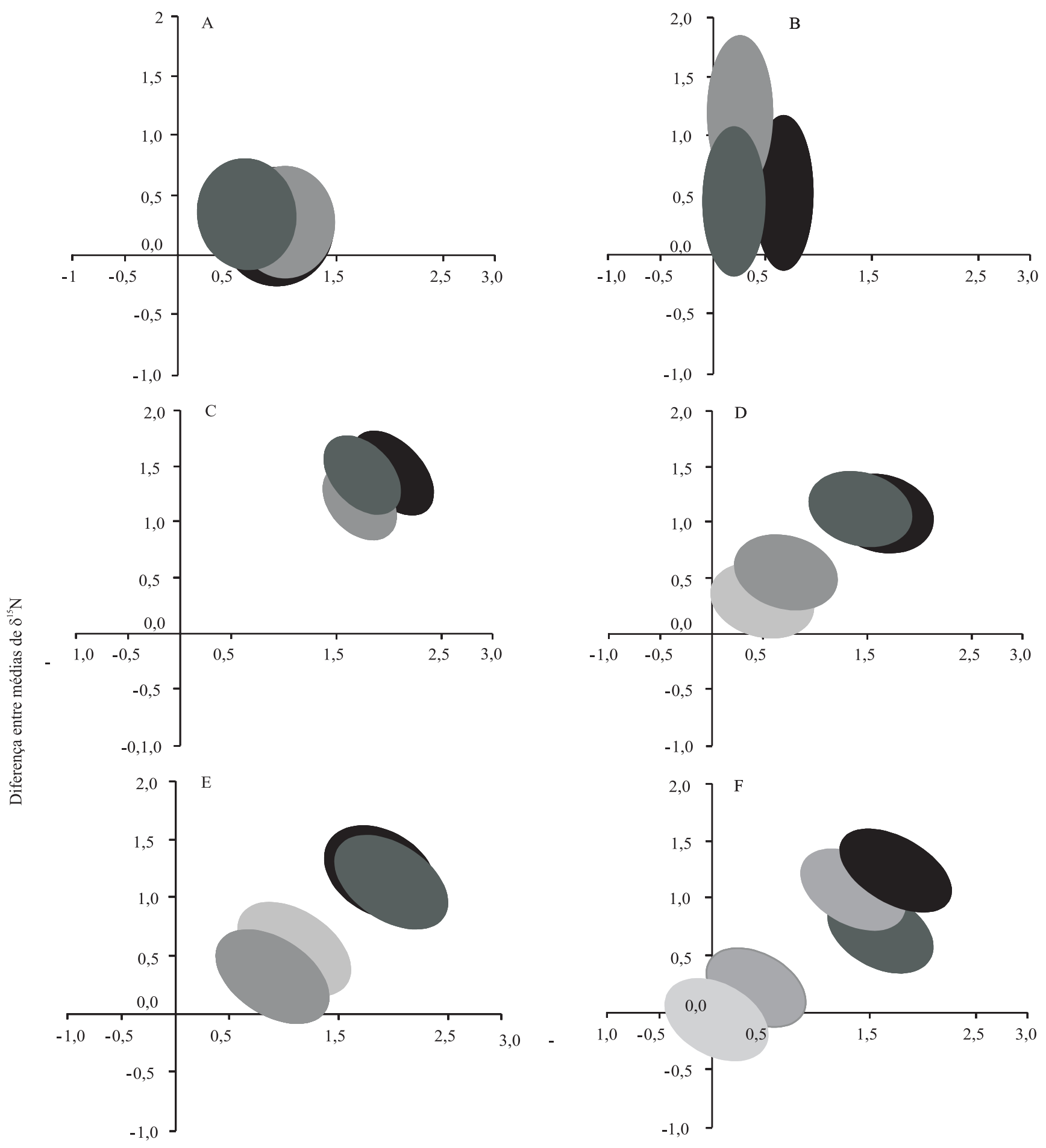

Diferença entre médias de $\delta^{13} \mathrm{C}$

\begin{tabular}{|llllllll}
\hline FV 1-42 & $\square$ & FV 1-35 & $\square$ & FV 1-21 & $\square$ & FV 22-42 & $\square$ FV 36-42 \\
\hline
\end{tabular}

Figura 1. Regiões de confiança formadas pela diferença entre os valores isotópicos de $\delta^{13} \mathrm{C}$ e $\delta^{15} \mathrm{~N}$, em penas de frangos de corte às idades de: A, 7 dias; B, 14 dias; C, 21 dias; D, 28 dias; E, 35 dias; e F, 42 dias. Cada tratamento está em comparação ao tratamento controle. 
estratégias de amostragem sem necessidade de sacrifício das aves, são de fácil aplicação em pontos críticos de controle nas empresas avícolas e servem de ferramenta de apoio às auditorias e à certificação de criações de frangos com dietas isentas de proteínas de origem animal.

A técnica dos isótopos estáveis, também foi aplicada, com o mesmo intuito, em estudos com poedeiras comerciais (Denadai, 2009), codornas de corte (Móri et al., 2007), Carrijo et al. (2006) e Oliveira (2010) ao estudar frangos de corte. Portanto, a técnica dos isótopos estáveis de carbono e nitrogênio, no processo de certificação, é uma ferramenta que pode ser utilizada com sucesso, na determinação de ingredientes de origem animal até o produto final.

\section{Conclusão}

A utilização da técnica dos isótopos estáveis de carbono e nitrogênio, em penas de frango de corte, detecta a utilização de farinha de vísceras na alimentação de frangos de corte, por um período de até 21 dias após a retirada desse ingrediente da dieta ou após 21 dias da inclusão da farinha de vísceras na dieta.

\section{Agradecimentos}

À Fundação de Amparo à Pesquisa do Estado de São Paulo, pelo financiamento da pesquisa.

\section{Referências}

BLOCK JUNIOR, C. Monitoramento da qualidade de rações brasileiras para ruminantes por espectrometria de massa. In: SIMPÓSIO SOBRE MANEJO E NUTRIÇÃO DE AVES E SUÍNOS E TECNOLOGIA DA PRODUÇÃO DE RAÇÕES, 2002, Campinas. Anais. Campinas: Colégio Brasileiro de Nutrição Animal, 2002. p.251-252.

BRICOUT, J.; KOZIET, J. Control of the authenticity of orange juice by isotopic analysis. Journal of Agricultural Food Chemistry, v.35, p.758-760, 1987.

BROOKES, S.T.; BARRIE, A.; DAVIES, J.E. A rapid ${ }^{13} \mathrm{C} /{ }^{12} \mathrm{C}$ test for determination of corn-syrups in honey. Journal of the Association of Official Analytical Chemists, v.74, p.627-629, 1991.

CARRIJO, A.S.; PEZZATO, A.C.; DUCATTI, C.; SARTORI, J.R.; TRINCA, L.; SILVA, E.T. Traceability of bovine meat and bone meal in poultry by stable isotope analysis. Revista Brasileira de Ciência Avícola, v.8, p.37-42, 2006.

CERUTI, F.C. Rastreabilidade de grãos: conceito, desenvolvimento de software e estudos de casos de manejo de insetos no armazenamento. 2007. Tese (Doutorado). Universidade Federal do Paraná, Curitiba.

CHOI, W.-J.; LEE, S.-M.; RO, H.-M.; KIM, K.-C.; YOO, S.-H. Natural ${ }^{15} \mathrm{~N}$ abundances of maize and soil amended with urea and composted pig manure. Plant and Soil, v.245, p.223-232, 2002.

CIMA, E.G.; AMORIM, L.S.B.; SHIKIDA, P.F.A. A importância da rastreabilidade para o sistema de segurança alimentar na indústria avícola. Revista FAE, v.9, p.1-12, 2006.

CRUZ, V.C.; SANTOS, G.S.; DUCATTI, C.; SARTORI, J.R.; ARAUJO, P.C.; STRADIOTTI, A.C. Rastreabilidade de farinha de origem animal no fígado de frangos de corte usando a técnica dos isótopos estáveis de carbono $\left({ }^{13} \mathrm{C} /{ }^{12} \mathrm{C}\right)$ e nitrogênio $\left({ }^{15} \mathrm{~N} /{ }^{14} \mathrm{~N}\right)$. Lavras. In: REUNIÃO ANUAL DA SOCIEDADE BRASILEIRA DE ZOOTECNIA, 45, 2008. Anais. Lavras: Sociedade Brasileira de Zootecnia, 2008. p.1-4.

DENADAI, J.C.; DUCATTI, C.; SARTORI, J.R.; PEZZATO, A.C.; MÓRI, C.; GOTTMANN, R.; MITUO, M.A.O. Rastreabilidade da farinha de carne e ossos bovinos em ovos de poedeiras alimentadas com ingredientes alternativos. Pesquisa Agropecuária Brasileira, v.44, p.1-7, 2009.

DENIRO, M.J.; EPSTEIN, S. Influence of diet on the distribution of carbon isotopes in animals. Geochimica et Cosmochimica Acta, v.42, p.495-506, 1978.

HANDLEY, L.L.; RAVEN, J.A. The use of natural abundance of nitrogen isotopes in plant physiology and ecology. Plant, Cell and Environment, v.15, p.965-985, 1992.

HOBSON, K.A.; CLARK, R.G. Assessing avian diets using stable isotopes. 1: Turnover of ${ }^{13} \mathrm{C}$ in tissues. The Condor, v.94, p.181-188, 1992a.

HOBSON, K.A.; CLARK, R.G. Assessing avian diets using stable isotopes II: factors influencing diet-tissue fractionation. The Condor, v.94, p.189-197, 1992 b.

KELLY, S.; PARKER, I.; SHARMAN, M.; DENNIS, J.; GOODALL, I. Assessing the authenticity of single seed vegetable oils using fatty acid stable carbon isotope ratios $\left({ }^{13} \mathrm{C} /{ }^{12} \mathrm{C}\right)$. Food Chemistry, v.59, p.181-186, 1997.

KOHL, D.H.; SHEARER, G. Isotopic fractionation associated with symbiotic $\mathrm{N}_{2}$ fixation and uptake of $\mathrm{NO}_{3}{ }^{-}$by plants. Plant Physiology, v.66, p.51-56, 1980.

KOZIET, J.; ROSSMANN, A.; MARTIN, G.J.; ASHURST, P.R. Determination of carbon-13 content of sugars of fruit and vegetable juices: a European inter-laboratory comparison. Analytica Chimica Acta, v.271, p.31-38, 1993.

MANCA, G.; CAMIN, F.; COLORU, G.; DEL CARO, A.; DEPENTORI, D.; FRANCO, M.A.; VERSINI, G. Characterization of the geographical origin of Pecorino Sardo cheese by casein stable isotope $\left({ }^{13} \mathrm{C} /{ }^{12} \mathrm{C}\right.$ and $\left.{ }^{15} \mathrm{~N} /{ }^{14} \mathrm{~N}\right)$ ratios and free amino acid ratios. Journal of Agricultural Food Chemistry, v.49, p.1404-1409, 2001.

MARTIN, G.J.; GUILLOU, C.; MARTIN, M.L.; CABANIS, M.T.; TEP, X.; AERNY, J. Natural factors of isotope fractionation and the characterization of wines. Journal of Agricultural and Food Chemistry, v.36, p.316-322, 1988. 
MÓRI, C.; GARCIA, E.A.; DUCATTI, C.; DENADAI, J.C.; PELÍCIA, K.; GOTTMANN, R.; MITUO, M.A.O.; BORDINHON, A.M. Traceability of animal byproducts in quail (Coturnix coturnix japonica) tissues using carbon $\left({ }^{13} \mathrm{C} /{ }^{12} \mathrm{C}\right)$ and nitrogen $(15 \mathrm{~N} / 14 \mathrm{~N})$ stable isotopes. Revista Brasileira de Ciência Avícola, v.9, p.263-269, 2007.

OLIVEIRA, R.P.; DUCATTI, C.; PEZZATO, A.C.; DENADAI, J.C.; CRUZ, V.C.; SARTORI, J.R.; CARRIJO, A.S.; CALDARA, F.R. Traceability of poultry offal meal in broiler feeding using isotopic analysis $\left(\delta^{13} \mathrm{C}\right.$ and $\left.\delta^{15} \mathrm{~N}\right)$ of different tissues. Revista Brasileira de Ciência Avícola, v.12, p.13-20, 2010.

ROSSMANN, A.; HABERHAUER, G.; HOLZL, S.; HORN, P.; PICHLMAYER, F.; VOERKELIUS, S. The potential of multielement stable isotope analysis for regional origin assignment of butter. European Food Research and Technology, v.211, p.32-40, 2000.

ROSTAGNO, H.S.; ALBINO, L.F.T.; DONZELE, J.L.; GOMES, P.C.; OLIVEIRA, R.F. de; LOPES, D.C.; FERREIRA, A.S.; BARRETO, S.L. de T. Tabelas brasileiras para aves e suínos: composição de alimentos e exigências nutricionais. 2.ed. Viçosa: UFV, 2005. 186p.

SAS INSTITUTE. SAS/STAT: user's guide. Version 8.0. Cary: SAS Institute, 2000.
SILVA, I.J.O. da. A rastreabilidade dos produtos agropecuários do Brasil destinados à exportação. In: SIMPÓSIO DE CONSTRUÇÕES RURAIS E AMBIÊNCIA, 2004, Piracicaba. Anais. Piracicaba: ESALQ, 2004. p.1-40.

SLEIMAN, M.; DUCATTI, C.; VENTURINI FILHO, W.G.; SILVA, E.T. Isotopic analysis of carbon $\left({ }^{13} \mathrm{C} /{ }^{12} \mathrm{C}\right)$ and nitrogen $(15 \mathrm{~N} / 14 \mathrm{~N})$ performed in raw material used for pilsen beer brewing. In: BRAZILIAN MEETING ON CHEMISTRY OF FOODS AND BEVERAGES, 5., 2004, São Carlos. Anais. São Carlos: Instituto de Química de São Carlos, 2004. p.1-4.

VOGEL, J.C.; EHLERINGER, J.R.; HALL, A.E.; FARQUHAR, G.D. Variability of carbon isotope fractionation during photosynthesis. In: EHLERINGER, J.; HALL, A.; FARQUHAR, G. Stable isotopes and plant carbon-water relations. San Diego: Academic Press, 1993. p.29-46.

WERNER, R.A.; SCHMIDT, H.L. The in vivo nitrogen isotope discrimination among organic plant compounds. Phytochemistry, v.61, p.465-484, 2002.

WHITE, J.W.; WINTERS, K.; MARTIN, P.; ROSSMANN, A. Stable carbon isotope ratio analysis of honey: validation of internal standard procedure for worldwide application. Journal of the Association of Official Analytical Chemists International, v.81, p.610-619, 1998.

Recebido em 4 de outubro de 2010 e aprovado em 31 de março de 2011 